\title{
Prognostic indicators in extrinsic allergic alveolitis
}

\author{
Martina Sterclova*, Vasakova Martina and Paluch Peter \\ *Correspondence: martinasafrankova@seznam.cz \\ Department of Respiratory Diseases of the 1st Medical Faculty, Charles University and Thomayer Hospital, Videnska 800, \\ 14000 Prague 4, Czech Republic.
}

\begin{abstract}
Background: Extrinsic allergic alveolitis belongs among the most often diagnosed interstitial lung diseases. However, little data concerning the impact of antigen-type, presentation of disease and treatment, on the patient's prognosis, is available.

Methods: Thirty eight patients were enrolled in a retrospective study. Data collected between January 2007 and December 2010 were analyzed. Patients were divided, at the time of diagnosis, into subacute and chronic extrinsic allergic alveolitis (EAA) groups according to their clinical presentation. One year after diagnosis, baseline lung function tests and treatment data were evaluated. Using high resolution computed tomography (HRCT), interstitial and alveolar changes were characterized with the help of a scoring system.

Results: We found no effects linked to the nature of the inhaled antigen or the treatment modality on lung functions 12 months after EAA diagnosis. Patients with subacute EAA had significantly better lung function tests after one year than patients with chronic EAA. Patients with chronic EAA had significantly higher HRCT interstitial scores than the subacute group (1.1 \pm 1.2 vs. $2.9 \pm 0.9)$. Correlations between HRCT interstitial scores and changes in lung functions were observed.

Conclusions: Only the clinical pattern of EAA and HRCT interstitial scores correlated with lung functions at the one year follow up.
\end{abstract}

Keywords: Extrinsic allergic alveolitis, high resolution computed tomography, inhalation antigen, lung functions, prognosis, treatment

\section{Introduction}

Extrinsic allergic alveolitis (EAA) is an interstitial lung disease resulting from repeated exposure to various inhaled antigens in predisposed individuals. EAA following exposure to molds, bacteria, bird proteins, animal dander and chemical compounds has been described in the literature [1]. Since there are no generally accepted diagnostic criteria for EAA, diagnosis remains a synthesis from careful evaluation of (i) the patient's medical and antigen exposure history, (ii) immunological tests, (iii) bronchoalveolar lavage fluid (BALF), (iv) transbronchial biopsy findings and (v) high resolution computed tomography (HRCT) patterns. In dubious cases, surgical lung biopsy can also be useful [2]. Even though EAA is one of the most commonly diagnosed interstitial lung diseases (especially compared to idiopathic pulmonary fibrosis (IPF)), there is currently little data concerning the nature of the inhalation antigen relative to disease presentation and prognosis. It is well known, that clinical presentations can differ depending on the type of inhaled antigen, duration of antigen exposure and the amount of inhaled antigen [3-6]. The first objective of this study was to determine if exposure to different inhaled antigens leads to different clinical presentations of EAA and different outcomes one year after diagnosis.

An HRCT of the chest is used in the diagnosis of all interstitial lung diseases, including EAA. It provides a non-invasive way to assess the extent of inflammatory changes and/or fibrotic involvement. The ability of the HRCT scoring system to quantify changes and make comparisons between patients or serial comparisons in individual data is a useful tool. Therefore the second objective of this study was to determine if initial HRCT changes in EAA patients could predict outcomes after one year (based on results from lung function tests).

There have been few studies concerning EAA. In some of studies it has been shown that corticosteroids do not improve the prognosis, although they have been shown to provide symptomatic relief and rapid recovery of lung functions $[7,8]$. The optimal treatment for EAA patients with dominant fibrotic involvement remains equivocal. In cases of other interstitial lung diseases with fibrotic involvement, the addition of cytotoxic agents to systemic corticosteroids (in cases of corticosteroids monotherapy failure) has been tried, although comprehensive studies on efficacy are missing. Preliminary results of the PANTHER study, concerning IPF treatment, showed that combined immuno-suppression might not be beneficial in all cases, considering the side effects of the drugs used [9]. The third and final objective of this study was to determine if treatment methods affect EAA prognosis at one year.

Summary of objectives: To assess the impact of the type of inhaled antigen at initial manifestation and on patients outcomes at a one year follow up. To investigate the usefulness of HRCT in predicting EAA outcomes at one year and to determine the impact of treatment regimens on EAA outcomes at one year.

\section{Materials and methods \\ Patients and design of the study}

Thirty eight patients (17 men, 21 women, mean age $56.5 \pm$

(C) 2013 Sterclova et al; licensee Herbert Publications Ltd. This is an Open Access article distributed under the terms of Creative Commons Attribution License (http://creativecommons.org/licenses/by/3.0). This permits unrestricted use, distribution, and reproduction in any medium, provided the original work is properly cited. 
Sterclova et al. Hypersensitivity 2013,

http://www.hoajonline.com/journals/pdf/2052-594X-1-1.pdf

doi: $10.7243 / 2052-594 X-1-1$

Table 1. Diagnostic criteria for chronic and subacute EAA used at Department of Respiratory Diseases, Thomayer Hospital Prague, Czech Republic.

\begin{tabular}{lll}
\hline & Subacute & Chronic \\
\hline $\begin{array}{l}\text { History of exposure } \\
\text { to inhalation antigen }\end{array}$ & + & $+/-$ \\
Crackles & $+/-$ & \\
DLco & $\downarrow$ & + \\
BALF lymphocytosis & + & $\downarrow$ \\
BALF CD4/CD8 & $\downarrow$ & $+/-$ \\
HRCT pattern & Centrilobular nodules & Centrilobular nodules \\
& GGO & GGO \\
& Mosaic perfusion & Mosaic perfusion \\
& Condensations & Condensations \\
& & Interstitial septa thickening \\
Histology pattern & Granuloma, OP, DIP & Granuloma, OP, DIP, NSIP, UIP \\
\hline
\end{tabular}

BALF- bronchoalveolar lavage fluid, DLco- lung diffusing capacity for carbon monoxide, HRCT-high resolution computed tomography, GGO- ground glass opacities, OP-organising pneumonia, DIP-desquamative interstitial pneumonia, NSIP-nonspecific interstitial pneumonia, UIP-usual interstitial pneumonia.

17.0 years) were enrolled in the study. Data were collected retrospectively from patients diagnosed with EAA at Thomayer Hospital, Prague, Czech Republic from January 2007 to December 2010. Twenty eight of the enrolled subjects were nonsmokers, 2 were current smokers and 8 were previous smokers. All participants underwent a complex diagnostic program. Diagnostic criteria of subacute and chronic form of EAA used at the Department of Respiratory Diseases are summarized in (Table 1 ).

Surgical lung biopsies were performed in 5 patients. The main tool for identification of the inhaled agent came from a detailed and repeated history evaluation. Serological methods are of limited diagnostic value, nevertheless higher concentrations of serum specific lgG should lead to a reevaluation of the patient's history with regard to exposure to particular antigens [10]. Patients were divided, at the time of diagnosis, into subacute and chronic EAA groups (subacute 18 patients, chronic 20 patients). HRCT scores were quantified at the time of enrollment into the study. One year after establishing the diagnosis, lung function tests and treatment data were evaluated.

\section{History assessment}

Patients were divided into 5 groups according to exposure data:

1. unknown antigen exposure (6 patients),

2. exposure to chemical compounds such as isocyanates (8 patients),

3. mold exposure (12 patients),

4. exposure to bird antigens (6 patients),

5. exposure to mammal epithelia and fur (6 patients).

\section{Treatment data}

Patients were divided into two groups based on treatment
Table 2. HRCT scoring system according to Gay SE et al., [13].

\begin{tabular}{lll}
\hline Score & Alveolar & Interstitial \\
\hline 0 & No alveolar disease & No interstitial disease \\
1 & GGO $<5 \%$ & Septal thickening, no honeycombing \\
2 & GGO $<25 \%$ & HC/ septal thickening $<25 \%$ \\
3 & GGO 25-49\% & HC/septal thickening 25-49\% \\
4 & GGO 50-5\% & HC/septal thickening 50-75\% \\
5 & GGO $>75 \%$ & HC/septal thickening $>75 \%$ \\
\hline
\end{tabular}

Scored fields $=$ peak of aortic arch, tracheal bifurcation, most prominent convexity of the right ventricle, and peak of the right cupola of diaphragm. Mean interstitial and alveolar scores were counted.

$\mathrm{GGO}=$ ground glass opacity,

$\mathrm{HC}=$ honeycombing.

strategy:

1. without pharmacological treatment: avoidance of of fending antigen was recommended, no pharmacologi cal treatment was initiated (9 patients).

2. pharmacologically treated:

a) avoidance of offending antigen was recommended + systemic corticosteroids (21 patients).

b) avoidance of offending antigen was recommended + systemic corticosteroids + azathioprine (8 patients).

\section{Lung function tests}

Forced vital capacity (FVC) and forced expiratory volume in one second (FEV1) were obtained during initial investigations and at the one year follow-up using a ZAN 100 Flowhandy II (Inspire, Oberthulba, Germany). ERS/ATS performance criteria for the test were followed [11]. The predicted spirometry values complied with those of the European Coal and Steel Community [12]. Diffusing capacity for CO (DLco) was obtained using a ZAN 300 CO-diffusion (Inspire, Oberthulba, Germany) on the same day as spirometry was performed. The DLco was measured using the single-breath method. Values were expressed as a percentage of the predicted value.

\section{High resolution computed tomography (HRCT)}

All enrolled subjects underwent a HRCT of the chest during the initial investigation. HRCT scans were performed using a LightSpeed VCT XT scanner. HRCT alveolar and interstitial scores were assessed by a pulmonologist experienced in radiology and carried out according to Gay SE et al., (Table 2) [13].

\section{Statistical methods}

Results are expressed as the mean \pm standard deviation (SD). Changes in lung functions at the one year follow-up were counted and expressed as $\triangle \mathrm{FVC}$ (FVC at 1 year followup - initial FVC), $\triangle \mathrm{FEV} 1$ (FEV1 at 1 year follow-up - initial FEV1), $\triangle \mathrm{FEV} 1 / \mathrm{FVC}$ (FEV1/FVC at 1 year follow-up - initial FEV1/FVC), and $\triangle \mathrm{DLCo}$ (DLco at 1 year follow-up - initial DLCo). Differences between two variables were assessed using the Mann-Whitney $\mathrm{U}$ test. The Kruskal-Wallis test was 

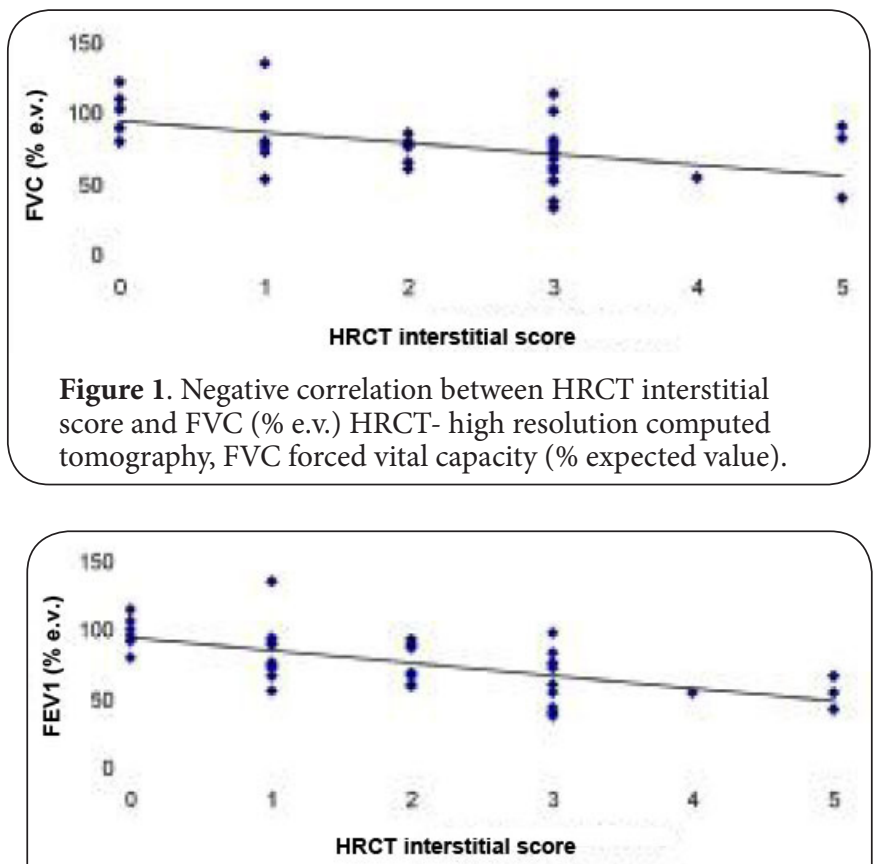

Figure 2. Negative correlation between HRCT interstitial score and FEV1 (\% e.v.) HRCT-high resolution computed tomography, FEV1- forced expired volume in 1 second (\% expected value).

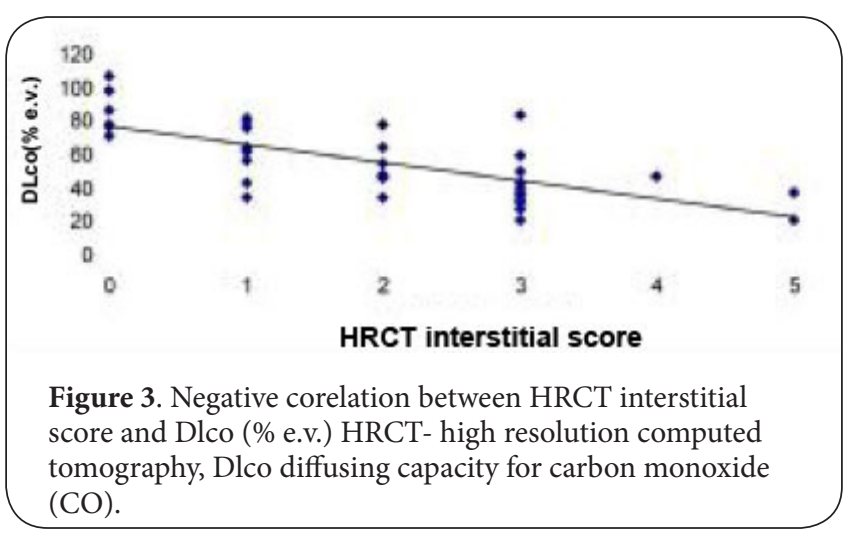

Table 3. HRCT scores in patients groups with different treatment regimens.

\begin{tabular}{lll}
\hline & HRCTa & HRCTi \\
\hline No treatment & $1.4 \pm 1.3$ & $1.3 \pm 1.0$ \\
Corticosteroids & $2.4 \pm 1.6$ & $2.1 \pm 1.4$ \\
CS+AZA & $2.2 \pm 1.3$ & $2.8 \pm 1.5^{*}$ \\
\hline
\end{tabular}

$\overline{\mathrm{HRCTa}}=$ high resolution computed tomography alveolar score, $\mathrm{HRCTi}=$ high resolution computed tomography interstitial score, $\mathrm{CS}+\mathrm{AZA}=$ systemic corticotherapy + azathioprine. ${ }^{*} \mathrm{p}<0.05$.

used to compare more than two variables. The Spearman's correlation was used to analyze correlations among variables.
For all statistical methods, $\mathrm{P}$ values $<0.05$ were regarded as significant.

\section{Data analysis}

To determine the impact of the type of inhaled antigen on EAA initial manifestation, FVC, FEV1, FEV1/FVC and Dlco of patients groups were assessed according to history of antigen exposure. HRCT scores were also compared among all patients groups. To reveal the impact of the inhaled antigen on EAA prognosis at the one year follow up, we compared $\triangle \mathrm{FVC}$ $\triangle F E V 1, \triangle F E V 1 / F V C$, and $\triangle D L c o$ of patients groups assessed according to history of antigen exposure. The Kruskal-Wallis test was used for this part of analysis.

The influence of the treatment regimen on EAA patient outcomes at the one year follow-up was completed by comparing $\triangle \mathrm{FVC}, \triangle \mathrm{FEV} 1, \triangle \mathrm{FEV} 1 / \mathrm{FVC}$, and $\triangle \mathrm{DLCO}$ of the previously established groups. The Kruskal-Wallis test was used for this part of analysis. The Kruskal-Wallis test was also used to describe and compare initial lung function and HRCT scores. The Spearman's test was used to analyze correlations among HRCT scores and lung functions.

\section{Results}

Impact of the antigen-type on EAA presentation and outcome at the one year follow-up

We found no effect relative to the nature of inhaled antigen on either lung functions or HRCT scores at the initial presentation or at the one year follow-up.

\section{Usefulness of HRCT in predicting outcomes at the one year follow-up}

No correlations among HRCT alveolar scores or changes in lung functions at the one year follow-up were documented. Nevertheless, we observed significant correlations between HRCT interstitial scores and $\triangle F V C(p=0.03), \triangle F E V 1(p=0.05)$ and $\triangle$ DLco $(p=0.05)$ (Figures $1,2,3)$.

Impact of treatment regimens on patient outcomes at the one year follow-up and the characterization of groups receiving different treatments

Initial lung functions of pharmacologically treated patients were lower than lung functions of the group without pharmacological treatment, the lowest values were observed in the corticosteroids + azathioprine group, although the differences did not reach statistical significance. HRCT scores of the group without pharmacotherapy, the systemic corticosteroid group and the systemic corticosteroids + azathioprine group are summarized in (Table 3 ). We found no statistically significant differences among HRCT alveolar scores from the different treatments groups. Patients receiving corticosteroids + azathioprine had significantly higher HRCT interstitial scores than untreated patients $(p=0.05)$.

We found no impact, relative to the initial treatment modality, on changes in lung function at the one year follow-up. 
Sterclova et al. Hypersensitivity 2013,

http://www.hoajonline.com/journals/pdf/2052-594X-1-1.pdf

doi: 10.7243/2052-594X-1-1

\section{Discussion}

The results of our study showed no effect related to the nature of the inhaled antigen and no effect related to pharmacological treatment relative to lung functions at the one year follow-up of EAA patients. The extent of fibrotic involvement, quantified by HRCT interstitial scores, was negatively correlated with lung functions 12 months after diagnosis. Although not all statistical differences were significant, patients receiving no treatment tended to have less severe HRCT involvement than the pharmacologically treated groups. Moreover, pharmacologically treated patients had lower lung functions (FVC, FEV1, DLCo) at the time of diagnosis, the lowest values were observed in the group of patients receiving corticosteroids + azathioprine. In fact the more severe lung involvement in these patients influenced the therapeutic approach.

More data concerning treatment results of patients with dominant fibrotic involvement are needed. Quantification of fibrotic involvement at the time of diagnosis could help predict patient outcomes. Even though corticosteroids may hasten symptom relief in some patients, their use (either alone or in combination with immunomodulators) should be individually discussed with patients having dominant fibrotic involvement and the risk/benefit ratio should be considered We emphasize the need for randomized controlled trials targeted on EAA treatment, because patients with dominant fibrotic involvement probably do not benefit from the currently popular use of systemic corticotherapy.

Most investigations in the literature involving large groups of patients are concerned with farmer's lung and bird fancier's lung. It is not known, if EAA caused by inhalation of other agents has the same clinical presentation and outcomes. A study of hypersensitivity pneumonitis (HP) showed that exposure to different antigens can lead to different clinical presentations at the time of diagnosis [3]. Some differences could also be seen in our patient groups, patients exposed to molds tended to have better lung functions at the time of diagnosis, as well as insignificantly lower alveolar and interstitial HRCT scores compared to others. On the other hand, patients with an unknown source of exposure exhibited more inflammation and fibrosis on HRCT scans. It can be argued, that a large number of patients with an unknown source of exposure were included in our study. The HP Study documented only 3 patients with EAA of unknown origin among 199 included patients [14]. However, in other studies, the etiological agent remained unknown in up to $21 \%$ of patients [15]. To the best of our knowledge, there are no studies in the literature concerning the natural course of EAA relative to antigen exposure. Even though our groups, based on the inhaled antigen, were small and enrolled patients received different treatment strategies, we observed insignificant differences in outcomes for subjects exposed to molds and subjects with an unknown antigen exposure. Patients with a mold exposure history tended to show a decline in $\mathrm{DL}_{c o}$ values at the one year follow up, while patients with an unknown antigen exposure had insignificant (although still the highest from all groups) increases in DLco values during the same period. Mouse model experiments have suggested a possible link between the type of inhaled antigen and the development of fibrotic lung impairment [16]. Moreover, EAA can, in some cases, progress without further antigen exposure [17]. This could explain the different outcomes after inhalation of different antigens. More patients and perhaps serial HRCT scanning would be useful in either confirming or ruling out this hypothesis.

The extent of fibrotic involvement, quantified using HRCT interstitial scores, was negatively correlated with lung functions at the one year follow-up (Figure 1,2,3). This finding corresponds with the study by Tateishi et al., which found a higher mortality risk in patients with HRCT honeycombing [18]. Hanak et al., noted that CT findings of pulmonary fibrosis were a useful prognostic indicator [19]. Other authors have also found that fibrosis on HRCT scans was potentially a sign of irreversible disease [20]. Perhaps a more descriptive classification based on HRCT patterns could be used for EAA patients (e.g. EAA with prevalence of nodules, EAA with dominant fibrotic involvement, etc.), since, as discussed above, initial HRCT patterns could be a good predictor of patient prognoses.

Systemic corticosteroids were used in patients with more severe decreases in lung functions and more inflammation and fibrosis on HRCT scans, documented by non-significantly increased HRCT alveolar and interstitial scores (Table 3). The noted lack of effect of treatment on lung functions at the one year follow-up was also observed by Kokkarinen et al., They showed that while EAA patients treated with corticosteroids exhibited a more marked improvement in DLco after one month of treatment, at the 5 year follow-up no statistically significant differences were found between those treated with corticosteroids and those who were untreated [7]. We found no prospective studies concerning the effect of combined corticosteroids and cytotoxic agent treatment on chronic EAA. Azathioprine has been used in the treatment of patients with collagen vascular diseases involving the lung interstitium, in sarcoidosis patients and in acute exacerbations of EAA [21-23]. Historically, the combination of corticosteroids and azathioprine has been recommended in the treatment of idiopathic pulmonary fibrosis (IPF). However, recently, the PANTHER study showed that this combination should not be used in IPF patients, because of its negative effect on patient mortality [24]. Our results found no significant benefits from combination treatment (i.e. corticosteroids and azathioprine) relative to lung functions in our EAA patients. Subjects receiving this combination initially had significantly lower lung functions and significantly higher HRCT interstitial scores compared to the untreated group. This might suggest that fibrosis in EAA patients is just as irreversible as in IPF patients and new therapeutic approaches that can directly 
Sterclova et al. Hypersensitivity 2013,

influence the fibro-proliferative pathogenetic pathway should be sought. A larger cohort of patients, than used in our study, would be needed to in order to draw definitive conclusions.

Our study has several limitations: first, the number of enrolled subjects did not enable us to draw comprehensive conclusions. Moreover, a longer time period would be needed to assess real contributions of initial HRCT results, the nature of the inhaled antigen and treatment strategies relative to predictions of patient outcomes and mortality.

The outlined limitations of this current study only enhance the urgent need of more EAA studies concerning the impact of antigen-type and randomized controlled studies to determine optimal treatment strategies.

\section{Conclusions}

Antigen-type probably did not influence EAA presentation at the time of diagnosis or at the one year follow-up, which may show towards uniform immune response of the lung regardless offending agent. HRCT patterns may be suggestive in determining prognoses of EAA patients, especially with regard to the extent of fibrotic changes. Similar observations were done also by other authors (especially by Hanak et al.,). EAA patients with dominant lung fibrosis may not profit from combined immuno-suppressive treatments. Especially this finding should lead to further evaluation on a larger cohort of patients.

\section{Competing interests}

The authors declare that they have no competing interests.

\section{Authors' contributions}

MS contributed to study design, patient investigations and enrollment, HRCT scoring and prepared the manuscript. MV helped with manuscript preparation and patient investigations. PP contributed to patient investigations. MS, MV and PP have given final approval of the version of the study to be published.

\section{Acknowledgement}

Presented study was supported by IGA

Grant No G 1207 (NT13433-4/2012).

\section{Publication history}

Received: 07-Feb-2013 Accepted: 05-Apr-2013

Published: 06-Apr-2013

\section{References}

1. Fink JN, Ortega HG, Reynolds HY, Cormier YF, Fan LL, Franks TJ, Kreiss K, Kunkel S, Lynch D, Quirce S, Rose C, Schleimer RP, Schuyler MR, Selman $M$, Trout $D$ and Yoshizawa Y: Needs and opportunities for research in hypersensitivity pneumonitis. Am J Respir Crit Care Med 2005, 171:7928. I Article | PubMed

2. Lacasse $Y$ and Cormier Y: Hypersensitivity pneumonitis. Orphanet J Rare Dis 2006, 1:25. | Article | PubMed Abstract | PubMed Full Text

3. Selman $M$, Lacasse $Y$, Pardo $A$ and Cormier $Y$ : Hypersensitivity pneumonitis caused by fungi. Proc Am Thorac Soc 2010, 7:229-36. I Article I PubMed

4. Schuyler M: Is hypersensitivity pneumonitis important? Ann Allergy Asthma Immunol 2002, 88:150-1. I Article I PubMed

5. Patel AM, Ryu JH and Reed CE: Hypersensitivity pneumonitis: current concepts and future questions. J Allergy Clin Immunol 2001, 108:66170. | Article | PubMed

6. Bourke SJ, Dalphin JC, Boyd G, McSharry C, Baldwin Cl and Calvert JE: Hypersensitivity pneumonitis: current concepts. Eur Respir J Suppl 2001, 32:81s-92s. | Article | PubMed

7. Kokkarinen JI, Tukiainen $\mathrm{HO}$ and Terho EO: Effect of corticosteroid treatment on the recovery of pulmonary function in farmer's lung. Am Rev Respir Dis 1992, 145:3-5. | Article I PubMed

8. Monkare S, Ikonen M and Haahtela T: Radiologic findings in farmer's lung. Prognosis and correlation to lung function. Chest 1985, 87:460-6. | Article | PubMed

9. Wells AU, Behr J, Costabel U, Cottin V and Poletti V: Triple therapy in idiopathic pulmonary fibrosis: an alarming press release. Eur Respir J 2012, 39:805-6. | Article | PubMed

10. Sterclova M, Vasakova M and Metlicka M: Significance of specific IgG against sensitizing antigens in extrinsic allergic alveolitis: serological methods in EAA. Rev Port Pneumol 2011, 17:253-9. I Article I PubMed

11. Miller MR, Crapo R, Hankinson J, Brusasco V, Burgos F, Casaburi R, Coates A, Enright P, van der Grinten CP, Gustafsson P, Jensen R, Johnson DC, Maclntyre N, McKay R, Navajas D, Pedersen OF, Pellegrino R, Viegi $\mathrm{G}$ and Wanger J: General considerations for lung function testing. Eur Respir J 2005, 26:153-61. I Article I PubMed

12. Standardized lung function testing. Official statement of the European Respiratory Society. Eur Respir J Suppl 1993, 16:1-100.

13. Gay SE, Kazerooni EA, Toews GB, Lynch JP, 3rd, Gross BH, Cascade PN, Spizarny DL, Flint A, Schork MA, Whyte RI, Popovich J, Hyzy R and Martinez FJ: Idiopathic pulmonary fibrosis: predicting response to therapy and survival. Am J Respir Crit Care Med 1998, 157:1063-72. I Article | PubMed

14. Lacasse Y, Selman M, Costabel U, Dalphin JC, Ando M, Morell F, Erkinjuntti-Pekkanen R, Muller N, Colby TV, Schuyler M and Cormier Y: Clinical diagnosis of hypersensitivity pneumonitis. Am J Respir Crit Care Med 2003, 168:952-8. I Article | PubMed

15. Hanak V, Golbin JM and Ryu JH: Causes and presenting features in 85 consecutive patients with hypersensitivity pneumonitis. Mayo Clin Proc 2007, 82:812-6. | Article | PubMed

16. Lemieszek M, Chilosi M, Golec M, Skorska C, Huaux F, Yakoub Y, Pastena C, Daniele I, Cholewa G, Sitkowska J, Lisowska W, Zwolinski J, Milanowski J, Mackiewicz B, Gora A and Dutkiewicz J: Mouse model of hypersensitivity pneumonitis after inhalation exposure to different microbial antigens associated with organic dusts. Ann Agric Environ Med 2011, 18:159-68. | Pdf | PubMed

17. Costabel U, Bonella F and Guzman J: Chronic hypersensitivity pneumonitis. Clin Chest Med 2012, 33:151-63. I Article I PubMed

18. Tateishi T, Ohtani Y, Takemura T, Akashi T, Miyazaki Y, Inase N and Yoshizawa Y: Serial high-resolution computed tomography findings of acute and chronic hypersensitivity pneumonitis induced by avian antigen. J Comput Assist Tomogr 2011, 35:272-9. | Article I PubMed

19. Hanak V, Golbin JM, Hartman TE and Ryu JH: High-resolution CT findings of parenchymal fibrosis correlate with prognosis in hypersensitivity pneumonitis. Chest 2008, 134:133-8. | Article | PubMed

20. Lacasse Y, Selman M, Costabel U, Dalphin JC, Morell F, ErkinjunttiPekkanen R, Mueller NL, Colby TV, Schuyler M, Jomphe V and Cormier $\mathrm{Y}$ : Classification of hypersensitivity pneumonitis: a hypothesis. Int Arch Allergy Immunol 2009, 149:161-6. I Article I PubMed

21. Douglas WW, Tazelaar HD, Hartman TE, Hartman RP, Decker PA, Schroeder DR and Ryu JH: Polymyositis-dermatomyositis-associated interstitial lung disease. Am J Respir Crit Care Med 2001, 164:1182-5. | Article I PubMed

22. Muller-Quernheim J, Kienast K, Held M, Pfeifer S and Costabel U: Treatment of chronic sarcoidosis with an azathioprine/prednisolone regimen. Eur Respir J 1999, 14:1117-22. | Article | PubMed

23. Churg A, Muller NL, Silva Cl and Wright JL: Acute exacerbation (acute lung injury of unknown cause) in UIP and other forms of fibrotic interstitial pneumonias. Am J Surg Pathol 2007, 31:277-84. | Article | PubMed

24. McGrath EE and Millar AB: Hot off the breath: triple therapy for idiopathic pulmonary fibrosis--hear the PANTHER roar. Thorax 2012, 67:97-8. | Article | PubMed 